\title{
Evolusi dan Eksistensi Model Abaya pada Masa Modern di Jazirah Arab
}

\begin{tabular}{|c|c|}
\hline $\begin{array}{l}\text { Ananda Vidyaratri Mega Pratiwi }{ }^{1 凶} \text { \& Rizki Amalia Sholihah } \\
{ }^{1} \text { Universitas Al Azhar Indonesia, Jakarta } \\
{ }^{2} \text { Universitas Gadjah Mada, Yogyakarta } \\
{ }^{凶} \text { megajackson93@gmail.com }\end{array}$ & $\begin{array}{r}\text { Riwayat naskah: } \\
\text { Diterima: } 1 \text { Juli } 2020 \\
\text { Disetujui: } 23 \text { November } 2020 \\
\text { Diterbitkan: } 12 \text { Desember } 2020\end{array}$ \\
\hline
\end{tabular}

\begin{abstract}
Abaya is often known as the loose black clothes worn by Arab women. This kind of fashion is usually worn by Arab women, equipped with a black cloth covering the head, whenever they leave the houses. Sometimes they combine it with the nikab. Abaya is also known as Islamic clothing as it suits the Islamic teaching in clothing norms. But there left a question as to what extent this fashion able to adapt the modernity, especially in the Arabian Peninsula, its "home countries". This research uses library research methodology where the data are obtained through relevant books and articles. The purpose of this study is to describe how Arabian women hold on to wear the abaya in their modern lives as well as to describe the changes in the current abaya model.
\end{abstract}

Keywords: abaya, Arabian Peninsula, clothes, modern

Abstrak: Abaya sering dikenal sebagai baju hitam longgar yang dikenakan oleh wanita Arab. Busana seperti ini biasanya dikenakan oleh wanita Arab, dilengkapi dengan kain hitam yang menutupi kepala, setiap kali keluar rumah. Terkadang mereka menggabungkannya dengan nikab. Abaya juga dikenal sebagai pakaian Islami karena sesuai dengan ajaran Islam dalam norma pakaian. Namun masih ada pertanyaan sejauh mana fashion ini mampu mengadaptasi modernitas, terutama di Jazirah Arab, "negara asalnya". Penelitian ini menggunakan metode penelitian pustaka dimana data diperoleh melalui buku dan artikel yang relevan. Tujuan dari penelitian ini adalah untuk mendeskripsikan bagaimana wanita Arab melestarikan abaya dalam kehidupan modern mereka serta untuk mendeskripsikan perubahan model abaya saat ini.

Kata kunci: abaya, Jazirah Arab, modern, pakaian 


\section{Pendahuluan}

Pakaian yang membalut tubuh merupakan hal yang tidak dapat dipisahkan dari kehidupan manusia. Seseorang memakai pakaian dengan berbagai macam model, dari model pakaian ala negara-negara Barat sampai model pakaian negara-negara Timur yang cenderung lebih tertutup, sebagaimana abaya yang awalnya sekedar berfungsi sebagai penutup dan pelindung tubuh wanita. ${ }^{1}$ Abaya dengan desain yang polos dan sederhana biasa dipakai oleh wanita Arab dari semua kalangan. Namun kini, seiring perkembangan mode, abaya memiliki fungsi lain sebagai alat komunikasi non verbal yang tercipta dari model, warna, dan corak dari pakaian tersebut, dimana makna yang terkandung dari pakaian menguatkan karakter si pemakai. ${ }^{2}$ Tak salah jika manusia selalu berlomba-lomba membeli pakaian yang sesuai dengan style yang diinginkan.

Dari masa ke masa, fashion selalu menunjukkan perkembangannya, baik dari segi ukuran, warna, model, maupun aksesoris yang melengkapinya. Pada abad pertama dan kedua sebelum masehi, pakaian masyarakat Arab hanya semacam dua kain yang menutupi bagian atas dan bagian bawah tubuh, kemudian diikat dengan tali di bagian pinggang. Pada masa Islam, setelah adanya adab dan contoh berpakaian oleh Rasulullah, pakaian orang Arab lebih tertutup daripada sebelumnya. Busana mereka meliputi pakaian yang dipakai sebagai pakaian biasa semacam gamis, mantel, dan lainnya yang dipakai menyesuaikan dengan iklim, acara, dan ekonomi. ${ }^{3}$

Semenjak fashion negara-negara Barat makin populer, fashion tersebut pun makin digandrungi oleh masyarakat di segala penjuru dunia, termasuk juga di Jazirah Arab yang meliputi Arab Saudi, Kuwait, Qatar, Yaman, Oman, Bahrain, dan UEA. Di antara dampak dari pengaruh tersebut adalah tren melepas jilbab atau penutup kepala sebagai bagian dari pakaian sehari-hari, yang diawali oleh wanita Nasrani karena agama mereka memang tidak memiliki aturan jilbab seketat agama Islam. ${ }^{4}$

Pun demikian, secara umum wanita Arab masih bertahan dengan corak mode pakaian tradisional mereka yang sering dipakai dalam kehidupan sehari-hari. ${ }^{5}$ Saat mengajar, acara formal, bahkan saat kegiatan non formal seperti lari atau jalan santai mereka masih menggunakan abaya yang dilengkapi dengan kerudung, jilbab, bahkan nikab. Meski tak jarang mereka juga memakai pakaian modern, namun abaya tetap dipakai sebagai outer-nya dan dilepas dalam suasana privat seperti acara atau kegiatan sesama wanita atau keluarga (mahram).

Sebagai pakaian tradisional wanita Arab yang mengalami dinamika mode dari masa ke masa, abaya pun kerap pula ditampilkan dalam peragaan busana masyhur Dubai Fashion Week dengan berbagai macam model dan gaya. ${ }^{6}$ Modifikasi abaya dimunculkan dari pola, model lengan, hiasan, hingga bahan yang digunakan dalam pembuatannya. ${ }^{7}$ Hal ini yang menjadikan abaya mampu

1 Elizabeth D Shimek, "The Abaya: Fashion, Religion, and Identity in a Globalized World". Lawrence University Honors Projects. 12 (2012). https://lux.lawrence.edu/luhp/12.

${ }^{2}$ Malcolm Barnard, Fashion Sebagai Komunikasi, Yogyakarta: Jalasutra, 2011.

${ }^{3}$ Yedida Kalfon Stillman, Arab Dress: A Short History. From the Dawn of Islam to Modern Times (Leiden: Brill, 2000).

${ }^{4}$ Stillman, Arab Dress: A Short History. From the Dawn of Islam to Modern Times.

${ }^{5}$ Shimek, "The Abaya: Fashion, Religion, and Identity in a Globalized World."

${ }^{6} \mathrm{H}$ Kim et al., "High-Valued Abaya Designs for the Middle Eastern Market-Focus on the UAE's Dubai Market," Archives of Design Research 25, no. 5 (2012): $101-11$. http://aodr.org/_common/do.php?a=full\&b=12\&bidx=20\&aidx=253

7 C A DeCoursey, "Attitudes of Professional Muslim Women in Saudi Arabia Regarding Wearing the Abaya," Asian Culture and History 9, no. 2 (2017): 16-28. https://doi.org/10.5539/ach.v9n2p16 
bersanding dengan produk fashion dunia lainnya. Bukan hanya itu, para desainer juga berlombalomba dalam pembuatan abaya yang dibutuhkan oleh wanita Arab. Dengan wujud abaya terkini, wanita Arab muda seperti remaja diberi pendidikan untuk menjaga salah satu barang budaya mereka. Pakaian nasional lambang wanita Arab yang dihadirkan dalam peragaan busana, mampu mengungkapkan kesan kekinian namun tidak meninggalkan warisan.

Abaya di masa modern seperti sekarang ini bukan hanya standarisasi melainkan sebagai wujud citra budaya yang disajikan untuk negara. Budaya yang tertuang pada pakaian inilah yang akan menjadi lambang kehormatan wanita Arab dalam hal nilai kesopanan, keanggunan, bahkan mode fashion yang harus dipertahankan. Meski belum lama ini di Arab Saudi, Pangeran Muhammad bin Salman justru melonggarkan aturan terhadap wanita untuk dapat melepas abaya, ${ }^{8}$ para desainer abaya tetap berusaha untuk mengembangkan abaya menjadi busana yang diminati wanita Arab maupun wanita muslim lainnya. Usaha mereka ini membuahkan hasil dengan tampilnya desain mereka di acara-acara peragaan busana kelas dunia.

Artikel ini bertujuan untuk mengetahui bagaimana dinamika perkembangan abaya ditinjau dari aspek kesejarahannya di masa silam hingga tren perubahan masa kini dan keberlanjutannya di masa mendatang. Untuk dapat mencapai tujuan tersebut, penulis menggunakan metode studi kepustakaan (library research) untuk mendapatkan data-data penelitian melalui sumber pustaka dan media baru seperti situs berita atau artikel dan situs berbagi video YouTube.

\section{Tinjauan Ringkas Dinamika Abaya}

Di masa Abad Pertengahan, masyarakat Arab masih menggunakan pakaian longgar seperti gamis dan lainnya. Pada masa-masa setelahnya, pakaian-pakaian ini mengalami modifikasi dan perubahan menyesuaikan dengan masa, mode fashion, dan pengaruh dari wilayah lain. Kini pakaian yang disebut dengan Abaya ini umumnya hanya dipakai oleh wanita Arab di beberapa negara wilayah Jazirah Arab seperti Saudi. ${ }^{9}$ Berbeda dengan di negara Qatar dan UEA yang tidak mengharuskan wanita menggunakan abaya. Kebijakan abaya sebagai pakaian nasional ini sejalan dengan penjelasan Leila Bassam tentang kemunculan abaya di Tanah Arab ${ }^{10}$ :

"Abaya hitam muncul di Saudi sejak 75 tahun yang lalu yang berasal dari Irak atau suriah. Abaya menjadi populer ketika Malik Abdul Aziz Al Saud membagikannya sebagai hadiah kepada pemimpin suku kerajaan pada awal tahun 1930-an. Secara bertahap, abaya menggantikan pakaian wajib dan menerapkan aturan ketat terhadap pakaian Islami di Arab Saudi”.

Sebelum tahun 1930, masyarakat Arab memakai pakaian yang modelnya sama seperti abaya, tetapi pakaian ini dapat dipakai oleh pria maupun wanita. Beberapa pakaian tersebut banyak dipengaruhi fashion dari luar wilayah Arab seperti Persia bahkan Romawi. ${ }^{11}$ Bukan hanya dari dua wilayah ini saja, pakaian model seperti ini juga dipengaruhi dari wilayah Mesopotamia.

${ }^{8}$ BBC News. Nisa' fi al-Su'udiyyah tartadīn al-Abā' al-Maqlūb \#BBC Trending (2019). Retrieved from https://youtu.be/cdxzm-oAGh0

9 Jasmine R Phillips, “The Abaya: A Balancing Act of Fashion and Modesty in the Arab Gulf Region,” 2013. Retrieved https://www.academia.edu/3845089/The_Abaya_A_Balancing_Act_of_Fashion_and_Modesty_in_the_Arab_Gulf_R egion

${ }^{10}$ Shimek, "The Abaya: Fashion, Religion, and Identity in a Globalized World."

${ }^{11}$ Stillman, Arab Dress: A Short History. From the Dawn of Islam to Modern Times. 
Pengaruh model pakaian dari wilayah lain telah mewarnai model pakaian Arab. Pakaian masyarakat di Jazirah Arab identik dengan model yang panjang dan longgar. Khususnya untuk wanita yang dilengkapi dengan jilbab sebagai penutup kepala dan serba panjang, dimana pada masa Assyiria diwajibkan wanitanya untuk memakai jilbab. ${ }^{12}$ Bahan yang digunakan untuk membuat jilbab dari wol, linen, dan kapas. ${ }^{13}$ Pria Arab juga memakai penutup kepala namun berbeda dengan wanitanya yang lebih tertutup.

Meski awalnya hanya dipakai oleh wanita di Jazirah Arab, di masa kini abaya sudah tersebar di beberapa negara di kawasan lain yang utamanya memiliki populasi penduduk beragama Islam. Tidak hanya di negara-negara yang mayoritas Muslim seperti Indonesia, tetapi termasuk juga di negara-negara Barat seperti Amerika Serikat dan Perancis. Namun seiring berjalannya waktu, terutama semenjak ada isu Islam dan terorisme, konotasi abaya menjadi negatif di beberapa media Barat. Negara-negara Barat kemudian menganggap pakaian ini menjadi "ditakuti" saat dipakai di negara-negara tersebut. ${ }^{14}$

Media Barat menggambarkan abaya sebagai lambang penaklukan, pengecualian masyarakat dari busana, lambang penindasan, dan kegagalan asimilasi terhadap budaya. Meski pada dasarnya, tiap negara bahkan daerah, memiliki keunikan tersendiri dalam hal berpakaian, sehingga hal seperti ini tidak bisa disamaratakan dengan negara lainnya. Mereka juga menanamkan "Islamophobia" dan memunculkan perspektif negatif terhadap pakaian wanita Arab khususnya abaya, sedangkan Arab yang mayoritas masyarakatnya muslim fokus terhadap busana yang dipakai memiliki nilai kesopanan dan sederhana dengan warna dan model yang longgar untuk menyembunyikan lekuk tubuh. ${ }^{15}$

Penggunaan abaya yang sering dilengkapi dengan kerudung dan nikab berwarna hitam dan menutupi seluruh tubuh wanita, sehingga membuat orang Barat terpancing untuk berfikir negatif dan curiga atas rahasia di balik abaya tersebut. Wanita Arab menggunakan abaya saat berpergian dan kegiatan ke luar rumah. Saat ke luar rumah, mereka akan menutup rapat-rapat tubuh mereka dengan abaya dilengkapi dengan jilbab terkadang juga dengan nikab. Berbeda saat mereka berkegiatan di rumah atau di rumah sanak saudara (mahram), mereka akan menggunakan pakaian yang lebih kasual. ${ }^{16}$ Beberapa media telah menayangkan beberapa berita tindakan anarkis orang-orang yang membenci wanita bernikab di negara-negara Barat. Salah satunya yaitu memaki hingga menarik nikab yang dikenakan wanita Muslim di depan umum. Kejadian ini merupakan wujud kurangnya toleransi terhadap perbedaan agama dan kepercayaan serta memandang busana tersebut dengan pandangan negatif.

12 Alfida Marifatullah, "Pakaian, Negara, Dan Identitas: Abaya Di Uni Emirat Arab Pasca Oil Booming II (2000-2010," UIN Syarif Hidayatullah 2017. http://repository.uinjkt.ac.id/dspace/handle/123456789/36771

13 Sara Pendergast, Tom Pendergast, and Sarah Hermsen, "Fashion, Costume, and Culture: Clothing, Headwear, Body Decorations, and Footwear through the Ages," Journal of Chemical Information and Modeling 53 (2013), https://doi.org/10.1017/CBO9781107415324.004.

${ }^{14}$ Phillips, "The Abaya: A Balancing Act of Fashion and Modesty in the Arab Gulf Region."

${ }^{15}$ DeCoursey, "Attitudes of Professional Muslim Women in Saudi Arabia Regarding Wearing the Abaya."

${ }^{16}$ Phillips, "The Abaya: A Balancing Act of Fashion and Modesty in the Arab Gulf Region." 


\section{Nilai Abaya bagi Masyarakat Jazirah Arab}

Abaya merupakan budaya yang lahir bukan berasal dari datangnya Islam dan bukan pakaian wanita Muslim seluruh dunia. ${ }^{17}$ Pun demikian, pakaian ini nyaris selalu dikelompokkan sebagai kategori pakaian Muslimah karena memang tampilannya yang memenuhi syarat dalam beberapa kategori dan ditetapkan juga oleh beberapa negara Arab sebagai pakaian nasional untuk wanita. Mayoritas masyarakat di sana adalah Muslim, sehingga pakaian ini juga dianggap sebagai pakaian Muslim. Hal ini sejalan juga dengan pernyataan yang menyebutkan bahwa budaya Arab menjadi penopang pula terhadap perkembangan agama Islam. ${ }^{18}$

Perbedaan anggapan sebuah "warisan" dalam konteks budaya dan agama telah menjadi perdebatan. ${ }^{19}$ Para pengkaji baik dari budaya maupun agama memiliki pegangan masing-masing terhadap pendapat yang mereka ajukan kepada publik. Menurut penulis, berdasarkan buku dan referensi ini dapat ditarik kesimpulan tentang ini. Pakaian longgar ini telah muncul di masa sebelum Islam. Di setiap masa, fashion selalu berevolusi yang terinspirasi dari pengaruh dari negara lain. Kini abaya telah dipakai oleh hampir seluruh wanita di Jazirah Arab. Selain undang-undang yang menetapkan abaya sebagai pakaian yang harus dipakai wanita di sana, dan karena pemakainya yang sering dijumpai adalah Muslimah, maka abaya sering disebut juga sebagai pakaian Islam. Begitu juga dengan thawb yang dipakai oleh pria yang tinggal di kawasan Jazirah Arab.

Wanita Arab cukup konsisten dalam mengenakan pakaian yang serba panjang dan longgar seperti abaya, karena pakaian ini melambangkan bentuk kesopanan bagi pemakainya. ${ }^{20}$ Menurut Barnard, bagian tubuh tertentu yang ditutupi dengan pakaian, merupakan bentuk dari kesopanan. ${ }^{21}$ Bahkan pakaian ini telah ditetapkan sebagai sebuah aturan bagi wanita yang tinggal di sebagian negara-negara Arab. Tetapi dapat dilihat lagi dengan peraturan dan norma sebagai wanita muslim yang sering diketahui oleh muslim lainnya dengan batasan aurat wanita yang boleh tampak hanya wajah dan telapak tangan. Mayoritas wanita Arab melengkapinya dengan nikab agar lebih terlindungi. Sebagian dari mereka tidak akan membuka nikabnya selain di dalam rumah atau di hadapan mahram mereka.

Abaya tradisional yang dipakai oleh wanita-wanita di Jazirah Arab menggambarkan sebuah kesederhanaan. Desainnya yang tidak berbelit-belit dan warnanya yang cenderung gelap bahkan hitam seluruhnya, sebagaimana ada dalam Gambar 1, membuat fashion ini tampak anggun. Pakaian wanita Arab teluk ini merupakan pakaian nasional yang dipandang sebagai representasi otentik budaya yang tidak pudar oleh pengaruh asing, ${ }^{22}$ sehingga wanita Arab dianggap telah mempertahankan tradisi berpakaian ala wanita Arab terdahulu dalam menghadapi modernisasi.

17 “Dalam Al Qur'an surat An Nur ayat 29-30 dan surat Al Ahzab ayat 37, tak ada rujukan kepada pakaian atau gaya pakaian tertentu. Jilbab pun sebenarnya sudah ada sebelum Islam datang dan dipakai bukan hanya oleh Islam saja, melainkan juga oleh agama samawi lain yang tinggal di sana". Selengkapnya periksa Phillips, "The Abaya: A Balancing Act of Fashion and Modesty in the Arab Gulf Region."

18 Muhammad Misbahuddin, "Pembangunan Budaya Dalam Masa Islam Awal". Al-Adabiya: Jurnal Kebudayaan Dan Keagamaan 1302 (2018), 332-47. https://doi.org/10.37680/adabiya.v13i02.29.

${ }^{19}$ Barnard, Fashion Sebagai Komunikasi.

${ }^{20}$ Stillman, Arab Dress: A Short History. From the Dawn of Islam to Modern Times.

${ }^{21}$ Phillips, "The Abaya: A Balancing Act of Fashion and Modesty in the Arab Gulf Region."

${ }^{22}$ Rana Khalid AlMutawa, "National Dress in the UAE: Constructions of Authenticity," New Middle Eastern Studies 6 (2016). https://doi.org/10.29311/nmes.v6i0.2668 
The shapeless one (1980-1990)



Black on black (1990-2003)

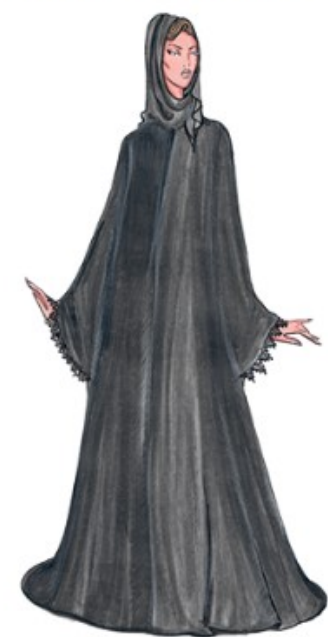

Gambar 1. Model abaya tradisional sederhana. ${ }^{23}$

Abaya yang berwarna hitam memiliki makna di dalamnya, karena negara di wilayah Jazirah Arab seperti Arab Saudi memiliki peraturan terhadap wanita. ${ }^{24}$ Wanita di sana sangat menjadi sorotan dan selalu diawasi oleh pihak keamanan. ${ }^{25}$ Sehingga pemilihan warna hitam bagi abaya merupakan pilihan yang tepat untuk menghindari perhatian publik. Modelnya yang longgar dan berwarna hitam tidak memperlihatkan lekuk tubuh mereka sehingga mereka terlindungi saat berada di luar rumah. Warna hitam merupakan warna gelap tingkat atas yang biasanya pakaian dengan warna ini bersifat tidak transparan sebagaimana warna-warna lainnya. Hal ini seperti yang diriwayatkan oleh Abu Hurairah bahwa Rasulullah mengajarkan agar perempuan sebaiknya tidak menggunakan pakaian yang transparan dan pakaian menyimpang dari aturan agama lainnya. ${ }^{26}$

Inilah alasan penggunaan abaya menjadi aturan ketat bagi wanita Arab Saudi. Negara yang dikenal sebagai tempat berawalnya agama Islam ini memang sangat berpegang teguh terhadap aturan dan norma agama. Abaya merupakan identitas diri terhadap budaya nasional yang terkandung dalam pakaian. ${ }^{27}$ Abaya, salah satu pakaian yang ditentukan sebagai pakaian nasional untuk populasi nasional tanpa memandang status sosial terus beroperasi dalam dinamika kekuatan antara warga dan negaranya.

Pemakaian abaya sebagaimana di Arab Saudi sudah menjadi ketetapan untuk wanita di sana. Hal ini diperkuat dengan penerbitan Fatwa nomer 21352 oleh Komite Fatwa Arab Saudi tentang panduan standar abaya yang harus tebal, tidak membentuk lekuk tubuh, dan tidak berlambang apapun. Bagi wanita Arab Saudi, pemakaian abaya merupakan ranah etika sosial

23 Safa Hassan, "Unconventional Evolution of Abayas," September 3, 2017, Retrieved from https://destinationksa.com/unconventional-evolution-of-abayas/.

${ }^{24}$ Phillips, "The Abaya: A Balancing Act of Fashion and Modesty in the Arab Gulf Region."

25 Hafsa Lodi, "The Evolution of the Abaya," February 14, 2018. Retrieved from https://www.thenationalnews.com/lifestyle/fashion/the-evolution-of-the-abaya-1.704710?videoId=5751130391001.

${ }^{26}$ Ratih Wulan. Alasan Wanita Saudi Pilih Abaya Hitam dan Pria Bergamis Putih. (2017) Retrieved from https://m.dream.co.id/lifestyle/alasan-wanita-arab- memakai-abaya-hitam-dan-putih-untuk-pria-170301d.html

${ }^{27}$ Noor Al-Qasimi, "Immodest Modesty: Accommodating Dissent and the 'abaya-as-Fashion in the Arab Gulf States," Journal of Middle East Women's Studies 6, no. 1 (2010): 46-74. https://doi.org/10.2979/MEW.2010.6.1.46 
karena pakaian ini adalah pakaian nasional bagi kaum wanitanya. Hal ini berbeda dengan negara Arab lain yang aturan pemakaian abayanya lebih longgar daripada Arab Saudi. Mereka memakai abaya hanya di acara formal saja, selain itu mereka memakai abaya dengan warna yang lebih variatif. Penutup kepala yang digunakan bukan jilbab saja. Seperti di Uni Emirat Arab (UEA), para wanita sering menggunakan shaila terkadang dihiasi dengan jepit rambut di sampingnya (Gambar 2). ${ }^{28}$

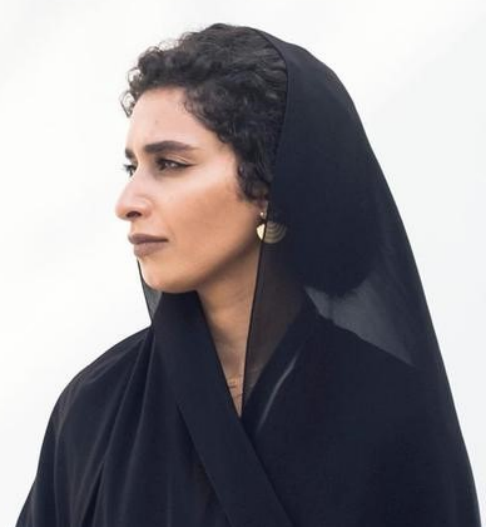

Gambar 2. Jilbab populer yang sering dipakai wanita Arab disebut dengan"shaila", ${ }^{29}$

Jilbab merupakan salah satu item budaya keanggunan warisan dan kebanggaan bagi wanita Arab. ${ }^{30}$ Jilbab yang dipakai wanita Arab memiliki banyak ragam, salah satunya adalah yang mereka sebut sebagai shaila. Shaila merupakan kain tipis yang digunakan untuk menutupi kepala wanita namun rambutnya tetap terlihat. ${ }^{31}$ Model kerudung semacam ini dapat dijumpai di negara yang wanitanya mayoritas memakai abaya seperti Arab Saudi, Qatar, UEA, dan negara Arab teluk lainnya. Bayangan di negara Barat tentang jilbab ialah kain hitam yang menutup seluruh tubuh semacam burqa, sedangkan bagi wanita Arab penggunaan jilbab disesuaikan dengan kondisi sosial, politik dan agama. Meskipun berbeda-beda pola variasinya, secara umum abaya telah menjadi identitas budaya di kawasan Jazirah Arab yang terus dijaga kelestariannya hingga kini. ${ }^{32}$

\section{Evolusi Abaya sebagai Produk Fashion}

Di satu sisi, wanita di Jazirah Arab konsisten dengan mempertahankan tradisi abaya serta patuh menjalankan norma pakaian tersebut, namun di sisi lain mereka juga memiliki jiwa konsumsi yang sangat tinggi terutama pada fashion. Saat di dalam rumah bersama keluarga bahkan dalam acara formal atau non formal keluarga, mereka biasa melepas abaya dan menggantinya dengan pakaian layaknya wanita-wanita di negara lain seperti memakai celana jeans atau pakaian ketat lainnya, bahkan gaun mewah. Dilihat dari tingkat perekonomiannya, wilayah ini memang sangat menggiurkan bagi investor asing. Mereka mampu memenuhi kebutuhan keluarga mereka dari kebutuhan primer sampai kebutuhan tersier yang salah satunya adalah dengan memakai dan mengoleksi pakaian mewah dari brand ternama.

${ }^{28}$ DeCoursey, "Attitudes of Professional Muslim Women in Saudi Arabia Regarding Wearing the Abaya."

${ }^{29}$ Lodi, "The Evolution of the Abaya."

30 Nadia Abgrab Noormohamed, "Muslim Women-Adapting Culture To The Modern Western World," Journal of Diversity Management (JDM) 3, no. 1 (2008): 67-74. https://doi.org/10.19030/jdm.v3i1.4982

${ }^{31}$ AlMutawa, "National Dress in the UAE: Constructions of Authenticity."

${ }^{32}$ Al-Qasimi, "Immodest Modesty" 
Sebenarnya, tidak semua wanita yang tinggal di wilayah Jazirah Arab dan negara-negara Timur Tengah setuju dengan memakai pakaian khas ini setiap hari. Mereka menginginkan memakai pakaian yang tetap menutup dan longgar namun menggeser kedudukan abaya sebagai fashion keseharian mereka. Abaya juga bukan pakaian wajib yang harus dipakai semua muslimah. Pada tahun 2018, Sheikh Abdullah Al-Mutlaq seorang pejabat tinggi dari Diwan al Maliki di Arab Saudi menyatakan bahwa wanita di negara itu tidak perlu lagi untuk mengenakan abaya. Hal ini menyebabkan pro dan kontra di negara tersebut. ${ }^{33}$ Bahkan Pangeran Muhammad bin Salman juga mengatakan bahwa wanita di sana tidak perlu lagi memakai abaya, mereka boleh memakai pakaian lain asalkan tetap menjaga kesopanan. ${ }^{34}$

Kekayaan minyak, revolusi mikroelektronika, dan ketersediaan sarana komunikasi, mewujudkan impian Jazirah Arab dalam membangun dunia Arab modern. ${ }^{35}$ Keunggulan industri ini menjadi keunggulan utama wilayah Jazirah Arab. Perubahan ekonomi membuat kehidupan masyarakatnya menjadi lebih baik bahkan melebihi cukup. Kehidupan yang berubah memunculkan gaya konsumerisme bagi masyarakat di sana. Mereka tidak tanggung-tanggung dalam membeli barang-barang seperti mobil mewah, rumah, bahkan mode busana. ${ }^{36}$

Jika ditelusuri bagaimana kehidupan wanita di Jazirah Arab memang menarik perhatian dunia. Dari segi ekonomi yang mulai menunjukkan persaingan dengan negara maju dan mencukupi ekonomi warganya seperti Arab Saudi, membuat konsumerisme di sana makin meningkat apalagi dipengaruhi oleh media sosial. ${ }^{37}$ Fashion dunia kini telah memasuki wilayah Jazirah Arab yang tidak bisa dipungkiri lagi, baik pria maupun wanita di sana sudah menjadi konsumen barang-barang dari Barat. Hal ini yang membuat abaya terpinggirkan dari daftar fashion wanita Arab.

Wanita berpakaian abaya memang masih dominan di berbagai lokasi di negara-negara Arab. Namun kini ada yang mulai berani secara terang-terangan memakai pakaian seperti jeans, kaos pendek, atau pakaian modis lainnya di balik abaya mereka. Sebagian dari mereka juga ada yang memakai hijab saja tanpa menggunakan nikab. Selebritis wanita yang ada di channel televisi Arab juga menunjukkan kebebasan dalam penggunaan abaya atau pakaian lain saat di luar rumah. Meskipun demikian masih banyak wanita Saudi yang masih menggunakan abaya tradisional karena tuntutan pemerintah terhadap mereka. ${ }^{38}$

Pakaian warna hitam berbahan jetblack memiliki beberapa macam seperti fursan, nida, maliki, lexus, dan hareer. Jika di negara-negara Arab sendiri, abaya yang khas lahir dengan model yang berwarna hitam, longgar, polos, dan sederhana. Namun Abaya modern kini berbeda, sebagaimana ada dalam Gambar 3. Desainnya yang sesuai di tubuh dan disulam dengan payet atau kristal Swarovski lebih diminati oleh kebanyakan wanita masa kini. ${ }^{39}$ Bahan-bahan yang berkualitas tinggi menjadikan abaya semakin diminati serta desainnya yang memukau menarik perhatian para konsumen khususnya wanita Arab.

\footnotetext{
${ }^{33}$ Lodi, "The Evolution of the Abaya."

${ }^{34}$ BBC News.

35 Theeb Mohammed Al Dossry, "Consumer Culture in Saudi Arabia (A Qualitative Study among Heads of Household)," University of Exeter, PhD Dissertation, 2012. http://hdl.handle.net/10036/4205

${ }^{36}$ Kim et al., "High-Valued Abaya Designs for the Middle Eastern Market"

${ }^{37}$ Al Dossry, "Consumer Culture in Saudi Arabia (A Qualitative Study among Heads of Household)."

${ }^{38}$ Shimek, "The Abaya: Fashion, Religion, and Identity in a Globalized World."

${ }^{39}$ Phillips, "The Abaya: A Balancing Act of Fashion and Modesty in the Arab Gulf Region."
} 

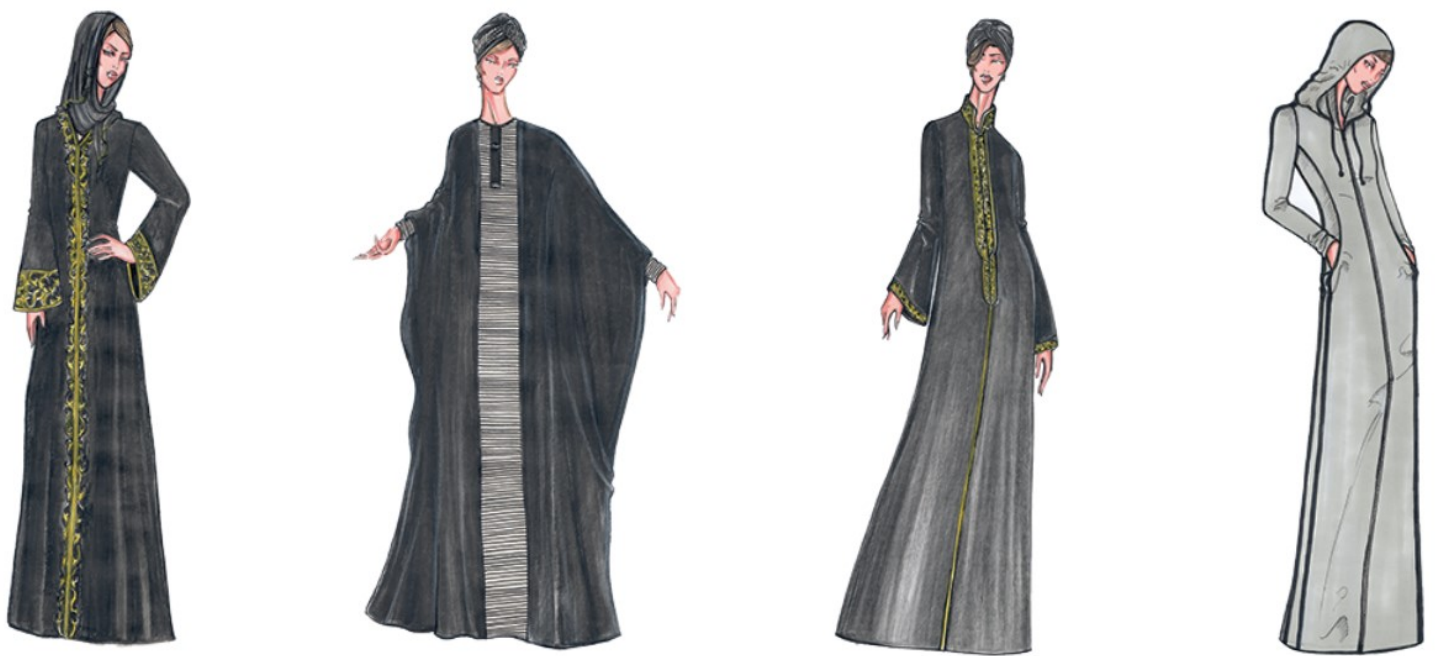

Gambar 3. Model abaya modern. ${ }^{40}$

Sekarang abaya tidak hanya menjadi pakaian untuk menyembunyikan bentuk fisik wanita saja, tetapi juga menjadi pakaian yang memiliki gaya yang didesain dengan berbagai potongan, warna, bahan kain serta dihiasi dengan berbagai dekorasi. ${ }^{41}$ Abaya abad 21 juga dihiasi dengan kristal, renda, sulaman, slogan dan logo seperti kaligrafi (attitudes), sebagaimana ada di Gambar 4. Ada pula abaya untuk anak-anak yang didesain dengan karakter animasi seperti kartun dari Walt Disney. ${ }^{42}$ Perubahan modifikasi terhadap abaya dipengaruhi oleh kekuatan globalisasi yang datang dari dunia Barat, serta terdiri atas warna, potongan, dan desain mode fashion Barat. ${ }^{43}$

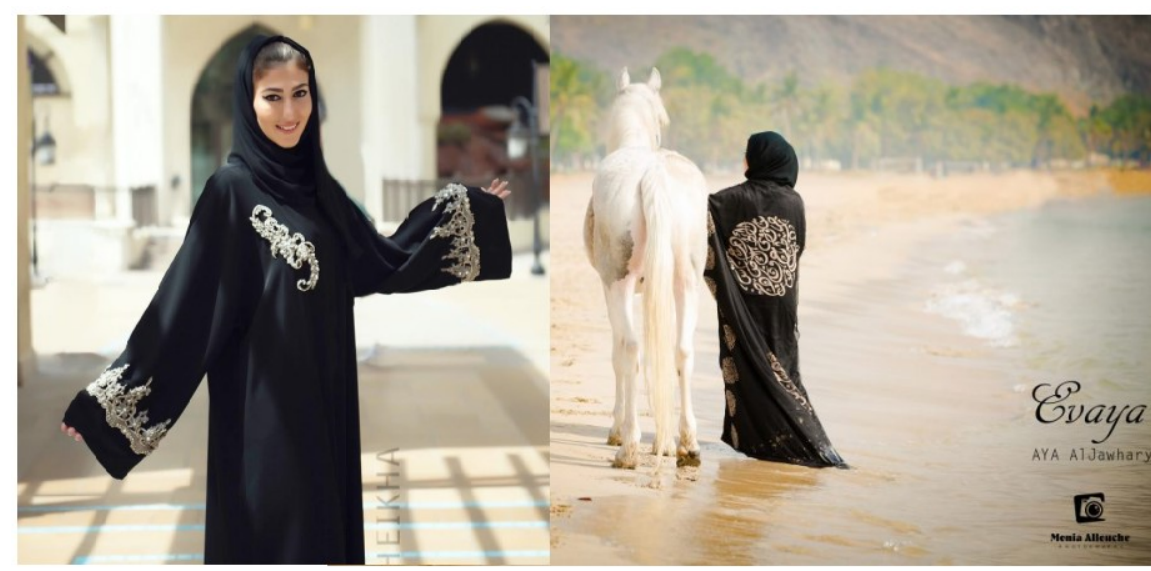

Gambar 4. "Al Sheikha” adalah abaya Turki yang mengkombinasikan warna klasik hitam dan payet putih/perak, dan "Evaya" dengan dekorasi kaligrafi karya Aya al Jawhari, desainer Yordania. ${ }^{44}$

Produsen abaya modern pun tidak terbatas pada negara di Jazirah Arab yang mengadopsi model fashion Barat saja, negara Timur Jauh seperti Tiongkok dan Korea Selatan pun juga menciptakan

\footnotetext{
${ }^{40}$ Hassan, "Unconventional Evolution of Abayas."

${ }^{41}$ Shimek, "The Abaya: Fashion, Religion, and Identity in a Globalized World."

${ }^{42}$ Kim et al., "High-Valued Abaya Designs for the Middle Eastern Market"

${ }^{43}$ Shimek, "The Abaya: Fashion, Religion, and Identity in a Globalized World."

${ }^{44}$ Arabisk London. "THE EVOLUTION OF THE ABAYA INTO A FASHION ESSENTIAL." February 7, 2018. Retrieved from https://www.arabisklondon.com/the-evolution-of-the-abaya-into-a-fashion-essential/
} 
model abaya modern yang kemudian diekspor ke negara-negara Arab dan bersaing dengan produsen ternama tuan rumah atau negara Barat seperti Perancis dan Italia yang merupakan kiblat fashion dan produsen bahan kain terbaik. ${ }^{45}$ Di kawasan, UEA menjadi negara yang pesat dalam kegiatan industri bisnis fashion abaya dan menarik para wisatawan asing untuk mencoba dan membeli pakaian ini karena modelnya yang tampak lebih cantik daripada di negara lain.

Seiring dengan perkembangan mutakhir ini, model abaya kemudian terbagi menjadi dua, yaitu abaya tradisional dan abaya kontemporer. ${ }^{46}$ Abaya tradisional modelnya seperti abaya yang sering dikenal oleh orang banyak, desainnya yang longgar, tanpa model, polos, dan berwarna hitam. Abaya seperti ini tidak menarik menurut wanita di Timur Tengah masa kini. Mereka cenderung tertarik dengan abaya kontemporer yang memiliki bermacam model dan gaya busana walaupun kainnya berwarna hitam. Abaya sekarang berevolusi dengan desain, warna, manikmanik dan desain lainnya, namun warna dasarnya tidak berubah. Bagi negara-negara di Timur Tengah seperti UEA, wanita dari kalangan elit memakai abaya premium dari brand global seperti Dolce, Gabbana, atau Carolina Herrera. ${ }^{47}$ Modelnya tetap longgar dan berlengan lebar, tetapi warnanya yang berbeda cenderung lebih terang dengan bermotif bunga. Sementara di Qatar, abaya memang merupakan pakaian nasional, tetapi para wanitanya lebih memilih pakaian lain sebagai pakaian keseharian mereka.

Model yang digunakan dalam desain abaya kini pun mulai berubah. Dulu pakaian ini serba longgar, kini ada yang bentuk pinggang dan modelnya seperti kaftan yang lebih diminati wanita Arab. ${ }^{48}$ Bahannya yang jatuh dan lembut seperti sutra dan kain lembut lainnya serta nyaman dipakai menjadi incaran wanita Arab, ${ }^{49}$ diharapkan pakaian ini tidak hanya diminati kembali oleh wanita Arab teluk, namun diminati pula oleh wanita di negara-negara asing khususnya wanita muslimah atau wanita yang menyukai pakaian panjang.

\section{Eksistensi Abaya di Masa Modern}

Abaya kini sudah menjadi fashion yang mampu bersaing dengan fashion modern lainnya bahkan disajikan di acara mode busana kelas dunia seperti Dubai Fashion Week. Berbagai brand ternama seperti Arabesque, Dan Couture, Das Collection, Hanayen, Homa Q Kanzi, La Reine, dan lainnya menggunakan bahan yang diimpor seperti kain tri-asetat, kain impor kualitas tinggi dari Italia, french crepe moroocan, kristal Swarovkski dari Austria, serta Dentai dan Mitsubishi silk dari Jepang. ${ }^{50}$

Zahar al Sayed, seorang desainer Saudi lulusan desain grafis dari London College of Communication juga meluncurkan model baru abaya yang multifungsi dengan sasaran untuk wanita aktif yang memiliki kegiatan di luar rumah dan multitasker. Abaya yang dibuatnya multifungsional dan dapat diubah menjadi jaket atau abaya dengan mudah dengan harga berkisar dari SR 800 atau USD 213 hingga SR 1.800 atau USD 480. Tahun 2007, desainer Saudi Eman

\footnotetext{
${ }^{45}$ Kim et al., "High-Valued Abaya Designs for the Middle Eastern Market"

${ }^{46}$ Phillips, "The Abaya: A Balancing Act of Fashion and Modesty in the Arab Gulf Region."

${ }^{47}$ Lodi, "The Evolution of the Abaya."

${ }^{48}$ Kim et al., "High-Valued Abaya Designs for the Middle Eastern Market"

${ }^{49}$ DeCoursey, "Attitudes of Professional Muslim Women in Saudi Arabia Regarding Wearing the Abaya."

${ }^{50}$ Kim et al., "High-Valued Abaya Designs for the Middle Eastern Market"
} 
Joharjy merancang abaya yang bebas digunakan untuk bersepeda yang ia sebut sebagai "abaya sporty" dan dipasarkan melalui media sosial. ${ }^{51}$

Setelah kemunculan abaya kontemporer yang lebih modis dan mengembalikan minat wanita Arab terhadap abaya, membuat evolusi ini menantang nilai dan kekhasan abaya. ${ }^{52}$ Kekhasan abaya yang polos dan sederhana dan bisa dipakai oleh wanita strata apapun tanpa memandang kelas sosial, kini berubah menjadi pakaian berkelas bahkan bersaing dengan produk fashion lainnya. Hal ini merupakan dinamika evolusi abaya yang menjadi perhatian khusus dari para desainer abaya agar pakaian ini tidak tenggelam oleh masa dan tertinggal dari fashion dunia. Abaya tetap bertahan sebagai pakaian wanita Jazirah Arab yang indah, memukau, dan selalu berkembang mengikuti perkembangan mode busana asing. Karena wanita terlahir menyukai keindahan dan memperhatikan busana, maka sudah dipastikan mereka akan mencari pakaian yang baik dan indah untuk dikenakan.

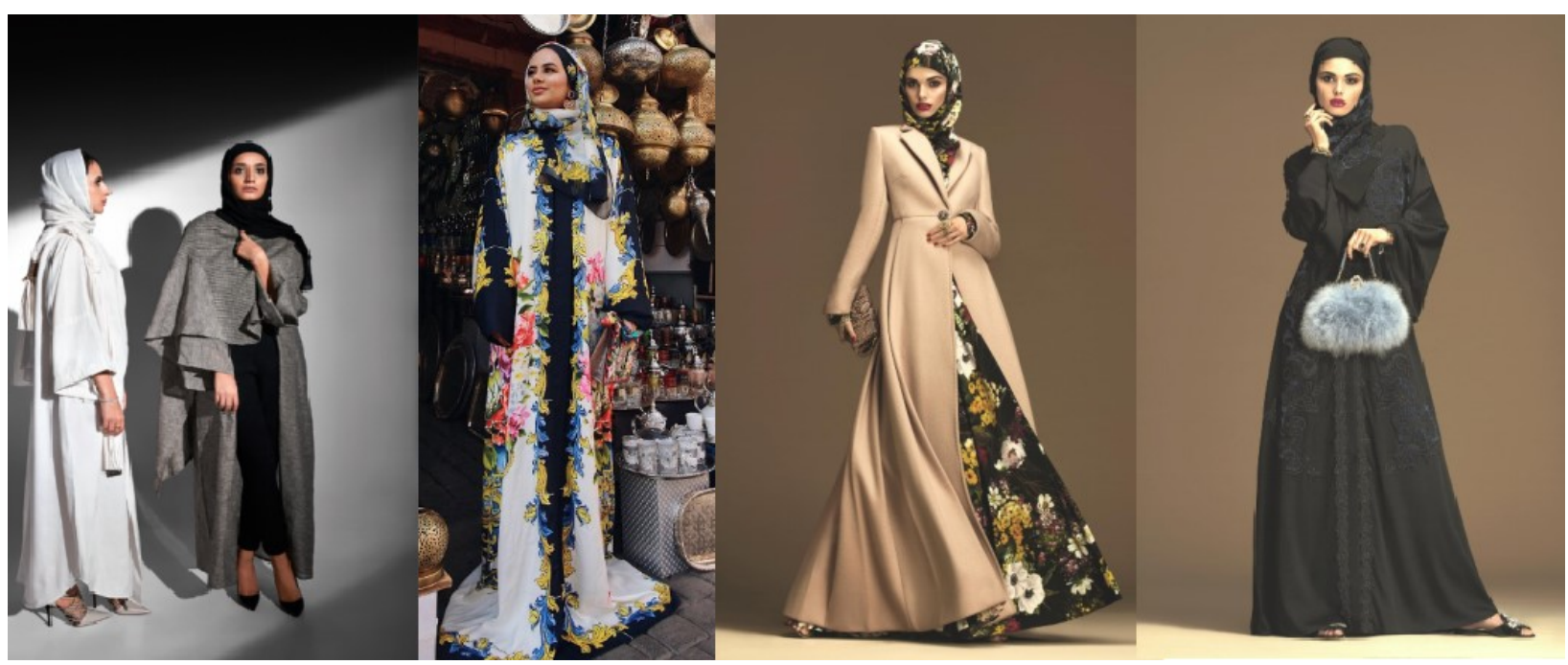

Gambar 5. Model abaya yang ada di rumah mode Dolce \& Gabbana. ${ }^{53}$

Jika diamati kembali dengan evolusi fashion Arab seperti abaya dan model yang disajikan, sebagaimana produk dari rumah mode Dolce \& Gabbana pada Gambar 5, maka tren ini dapat mengurangi persepsi negatif terhadap abaya. Apalagi abaya kini telah diklaim sebagai pakaian wanita muslim di Arab. Model abaya yang beraneka macam, beraneka warna, kaya akan pernakpernik, ditambah hijab atau jilbab yang unik membuat abaya semakin dikenal menjadi mode busana Arab dan mampu bersanding dengan fashion modis lainnya. Wanita Arab kini juga memperhatikan pemilihan abaya saat berkegiatan seperti halnya pesta pernikahan, kegiatan formal atau non formal, dalam hal ukuran lengan, potongan, warna, motif, renda sulaman, dan bahanbahan lain yang melengkapi abaya menjadi sempurna. ${ }^{54}$ Secara bertahap, wanita Arab telah berpindah dari pakaian tradisional ke fashion yang lebih modern dengan berbagai warna dan gaya kerudung. ${ }^{55}$

51 Fotun Eshmawi. New-look abaya that blends faith, fashion and function. (2018) Retrieved from https://www.arabnews.com/node/1345466/lifestyle

52 Shimek, "The Abaya: Fashion, Religion, and Identity in a Globalized World."

${ }^{53}$ Lodi, "The Evolution of the Abaya."

${ }^{54}$ DeCoursey, "Attitudes of Professional Muslim Women in Saudi Arabia Regarding Wearing the Abaya."

${ }^{55}$ Kim et al., "High-Valued Abaya Designs for the Middle Eastern Market" 
Munculnya abaya modern membuat abaya menjadi kebanggaan dan masih bertahan menjadi fashion wanita Arab sampai sekarang. Mayoritas wanita Arab tidak merasa keberatan untuk memakai abaya dan kebanyakan wanita muda Arab kini menganggap abaya sebagai mode. ${ }^{56}$ Bagi mereka, memakai abaya adalah suatu kebanggaan mode busana yang membudaya dan dapat beradaptasi dengan pakaian modis dari fashion asing. Gaya mode busana tradisional abaya memberi jalan untuk bereksperimen yang memenuhi tujuan religius dan tuntutan fashion dunia. Meskipun dinamika pelestarian dan modernisasi terhadap abaya masih menjadi perdebatan, abaya harus kokoh sebagai lambang kelestarian budaya berbusana yang mampu beradaptasi dengan perkembangan zaman.

\section{Kesimpulan dan Penutup}

Abaya merupakan salah satu pakaian yang lahir dari budaya, namun dapat mengikuti evolusi dan mampu bersanding dengan fashion lainnya. Walaupun mulanya berawal dari pakaian hitam dan longgar serta polos tak bercorak apapun, di masa kini abaya sudah memiliki model sendiri. Abaya premium atau abaya modern lahir dari tangan-tangan kreatif para desainer, baik dari Jazirah Arab maupun luar negeri. Penampilan abaya di tiap ajang pameran busana seperti fashion week telah mengenalkan abaya kepada khalayak dunia. Tujuan pembuatan desain abaya yang baru adalah agar wanita di Jazirah Arab tetap bangga menggunakan pakaian yang lahir dari budaya mereka sendiri, mampu menggambarkan keselarasannya dengan aturan agama dan nilai-nilai kesopanan wanita Arab, namun tetap dapat mengikuti perkembangan global. Abaya yang berevolusi dari abaya tradisional ke abaya modern juga menjalani waktu yang lama.

Artikel ini masih memiliki banyak kekurangan, terutama dari sisi dinamika terkini tentang abaya di lokasi langsung. Penulis berharap agar penelitian selanjutnya dapat menyempurnakan artikel ini, baik pakaian Arab umumnya maupun abaya secara spesifik.

\section{Referensi}

Al Dossry, Theeb Mohammed. "Consumer Culture in Saudi Arabia (A Qualitative Study among Heads of Household),", University of Exeter, PhD Dissertation, 2012. http://hdl.handle.net/10036/4205

AlMutawa, Rana Khalid. "National Dress in the UAE: Constructions of Authenticity." New Middle Eastern Studies 6 (2016). https://doi.org/10.29311/nmes.v6i0.2668

Al-Qasimi, Noor. "Immodest Modesty: Accommodating Dissent and the 'abaya-as-Fashion in the Arab Gulf States." Journal of Middle East Women's Studies 6, no. 1 (2010): 46-74. https://doi.org/10.2979/MEW.2010.6.1.46

Arabisk London. "THE EVOLUTION OF THE ABAYA INTO A FASHION ESSENTIAL." February 7, 2018. Retrieved from https://www.arabisklondon.com/the-evolution-of-theabaya-into-a-fashion-essential/

Barnard, Malcolm. Fashion Sebagai Komunikasi. Yogyakarta: Jalasutra, 2011.

BBC News. Nisa' fi al-Su'udiyyah tartadīn al-Abā' al-Maqlūb \#BBC Trending (2019). Retrieved from https://youtu.be/cdxzm-oAGh0

\footnotetext{
${ }^{56}$ DeCoursey, "Attitudes of Professional Muslim Women in Saudi Arabia Regarding Wearing the Abaya."
} 
DeCoursey, C A. "Attitudes of Professional Muslim Women in Saudi Arabia Regarding Wearing the Abaya." Asian Culture and History 9, no. 2 (2017): 16-28. https://doi.org/10.5539/ach.v9n2p16

Eshmawi, Fotun. New-look abaya that blends faith, fashion and function. (2018) Retrieved from https://www.arabnews.com/node/1345466/lifestyle

Hassan, Safa. "Unconventional Evolution of Abayas." September 3, 2017, Retrieved from https://destinationksa.com/unconventional-evolution-of-abayas/.

Kim, H, H Kim, S Han, J Jeon, and H Kang. "High-Valued Abaya Designs for the Middle Eastern Market-Focus on the UAE's Dubai Market." Archives of Design Research 25, no. 5 (2012): 101-11. http://aodr.org/_common/do.php? $a=f u l l \& b=12 \& b i d x=20 \&$ aidx $=253$

Lodi, Hafsa. "The Evolution of the Abaya." February 14, 2018. Retrieved from https://www.thenationalnews.com/lifestyle/fashion/the-evolution-of-the-abaya1.704710 ?videoId $=5751130391001$

Marifatullah, Alfida. "Pakaian, Negara, Dan Identitas: Abaya Di Uni Emirat Arab Pasca Oil Booming II (2000-2010)," UIN Syarif Hidayatullah Jakarta, Skripsi, 2017. http://repository.uinjkt.ac.id/dspace/handle/123456789/36771

Misbahuddin, Muhammad. "Pembangunan Budaya Dalam Masa Islam Awal". Al-Adabiya: $\begin{array}{llllll}\text { Jurnal Kebudayaan Dan Keagamaan } & 13 & 02 & \text { (2018): } & 332-47 .\end{array}$ https://doi.org/10.37680/adabiya.v13i02.29.

Noormohamed, Nadia Abgrab. "Muslim Women-Adapting Culture To The Modern Western World." Journal of Diversity Management (JDM) 3, no. 1 (2008): 67-74. https://doi.org/10.19030/jdm.v3i1.4982

Pendergast, Sara, Tom Pendergast, and Sarah Hermsen. "Fashion, Costume, and Culture: Clothing, Headwear, Body Decorations, and Footwear through the Ages." Journal of $\begin{array}{lllll}\text { Chemical Information } & \text { and }\end{array}$ https://doi.org/10.1017/CBO9781107415324.004.

Phillips, Jasmine R. "The Abaya: A Balancing Act of Fashion and Modesty in the Arab Gulf Region," 2013. Retrieved from https://www.academia.edu/3845089/The_Abaya_A_Balancing_Act_of_Fashion_and_Mod esty_in_the_Arab_Gulf_Region

Shimek, Elizabeth D., "The Abaya: Fashion, Religion, and Identity in a Globalized World". Lawrence University Honors Projects. 12 (2012). https://lux.lawrence.edu/luhp/12.

Stillman, Yedida Kalfon. Arab Dress: A Short History. From the Dawn of Islam to Modern Times. Leiden: Brill, 2000.

Wulan, Ratih. Alasan Wanita Saudi Pilih Abaya Hitam dan Pria Bergamis Putih. (2017) Retrieved from https://m.dream.co.id/lifestyle/alasan-wanita-arab- memakai-abaya-hitamdan-putih-untuk-pria-170301d.html. 